\title{
STUDI PARAMETRIK JARAK PENGARUH PENURUNAN DAN PERGERAKAN LATERAL AKIBAT VACUUM PRE-LOADING PADA DAMAGE AREA SEKITAR
}

\author{
Mario Oktavianus Lay ${ }^{1}$, Inda Sumarli ${ }^{2}$, dan Ali Iskandar ${ }^{3}$ \\ ${ }^{1}$ Program Studi Sarjana Teknik Sipil, Universitas Tarumanagara, Jl. Letjen S. Parman No.1 Jakarta \\ vian.lay@yahoo.com \\ ${ }^{2}$ Program Studi Sarjana Teknik Sipil, Universitas Tarumanagara, Jl. Letjen S. Parman No.1 Jakarta \\ indasumarli@gmail.com \\ ${ }^{3}$ Program Studi Sarjana Teknik Sipil, Universitas Tarumanagara, Jl. Letjen S. Parman No.1 Jakarta \\ ali.iskandar1999@gmail.com
}

\begin{abstract}
Soil-fill is type of soil with low bearing capacity, therefore it's need soil improvement to resolve the settlement. Soil improvement divided into 2 categories, namely methods that use new material and reinforcement. Commonly used method is PVD combined with vacuum pre-loading. Pre-loading is an application to increase surcharge load which aims to reduce the primary settlement occurs. Pre-loading not only causes settlement, but also cause lateral displacement which cause damage to the outside area around the improvement area. Thus, an analysis of distance effect between the improvement boundary and outside of improvement area in needed to prevent damage to utility around the site. Deformation analysis will be assisted by 2-Dimensional finite element program. Width of the improvement area is 80 meters with a depth of PVD is 14,5 meters to verify parameters. With the parameters that have been verified, an analysis is carried out on PVD with depth of $5 \mathrm{~m}$ to $30 \mathrm{~m}$ to determined distance effect of settlement and lateral displacement from boundary of the improvement area to until the value of the settlement and lateral displacement reaches $<2 \mathrm{~cm}$. Result of studies on general is to find distance effect caused by vacuum preloading in areas outside the improvement boundary.
\end{abstract}

Keywords: PVD; finite element program (2D); distance effect; settlement; lateral displacement

\begin{abstract}
ABSTRAK
Tanah hasil urugan merupakan jenis tanah lunak dengan daya dukung yang rendah, sehingga terjadi penurunan konsolidasi dan membutuhkan perbaikan. Perbaikan tanah dibagi menjadi 2 kategori, yaitu metode yang menggunakan material baru dan menggunakan pemanfaatan perkuatan. Metode yang umum digunakan adalah PVD yang dikombinasikan dengan vacuum pre-loading. Pre-loading adalah aplikasi penambahan beban surcharge yang bertujuan agar terjadinya penurunan primer. Pre-loading tidak hanya menyebabkan penurunan, tetapi juga menyebabkan terjadinya perpindahan secara lateral kearah luar yang dapat menyebabkan kerusakan pada area luar disekitar daerah perbaikan. Sehingga, dibutuhkan analisis jarak pengaruh antara batas lahan perbaikan dengan daerah luar perbaikan, untuk mencegah kerusakan pada struktur atau utilitas disekitar lokasi perbaiki. Analisis deformasi menggunakan program elemen hingga 2D. Lebar area perbaikan 80 meter dengan kedalaman PVD 14,5 meter untuk melakukan verifikasi parameter. Dengan parameter yang telah diverifikasi, dilakukan analisis pada PVD dengan kedalaman 5m hingga 30m untuk mengetahui jarak pengaruh penurunan dan pergerakan lateral dari batas lahan perbaikan hingga nilai penurunan dan pergerakan lateral $<2 \mathrm{~cm}$. Hasil studi secara umum menunjukkan seberapa besar jarak pengaruh yang diakibatkan oleh vacuum pre-loading pada daerah diluar batas perbaikan.
\end{abstract}

Kata kunci: PVD; program elemen hingga 2D; jarak pengaruh; penurunan; pergerakan lateral

\section{PENDAHULUAN}

Tanah hasil urugan pada daerah yang sebelumnya merupakan rawa umumnya merupakan jenis tanah lunak yang memiliki daya dukung tanah rendah serta penurunan yang terjadi relatif besar. Apabila tidak dilakukan perbaikan tanah terlebih dahulu pada jenis tanah ini. maka bangunan yang di bangun di tanah hasil urugan akan mengalami penurunan konsolidasi. Konsolidasi merupakan fenomena dalam mekanika tanah yang menimbulkan permasalahan geoteknik yang terjadi pada waktu yang lama. Konsolidasi terjadi akibat berkurangnya volume rongga air pori dari 
tanah jenuh yang memiliki permeabilitas rendah akibat beban yang bekerja dalam periode waktu tertentu, sehingga diperlukan perbaikan tanah. Pada penelitian ini membahas metode vacuum pre-loading dan pemanfaatan PVD.

Pre-loading adalah aplikasi penambahan beban surcharge sebelum konstruksi dilakukan, agar terjadinya penurunan primer. Karena tanah kompresif biasanya ditandai dengan permeabilitas yang sangat rendah, waktu yang diperlukan untuk konsolidasi sangat lama, walaupun dengan penambahan beban surcharge load yang cukup tinggi. Oleh karena itu, penerapan pre-loading saja mungkin tidak dapat dilakukan karena jadwal konstruksi yang ketat, PVD dikombinasikan dengan pre-loading yang bertujuan untuk mempercepat konsolidasi selama masa konstruksi, namun terdapat beberapa hal yang perlu diperhatikan yaitu, jarak antar saluran, pola pemasangan, serta jarak antara batas lahan yang diperbaiki dengan eksisting bangunan disekitar.

Mekanisme pembebanan dengan sistem vacuum sebagai pre-loading berupa tekanan negative hisap tidak hanya menyebabkan penurunan pada tanah dasar, namun juga menyebabkan terjadinya perpindahan lateral kearah luar sehingga menyebabkan kerusakan pada area disekitar daerah perbaikan. Penelitian ini akan fokus pada jarak pengaruh antara batas lahan perbaikan dengan daerah luar perbaikan, untuk mencegah kerusakan pada struktur atau utilitas di sekitar lokasi perbaikan dengan melakukan pengaturan kedalaman PVD yang diperirakan mampu mengurangi jarak pengaruh.

Berdasarkan latar belakang masalah di atas, penulis akan melakukan analisis mengenai jarak pengaruh penurunan dan pergerakan lateral yang diakibatkan oleh vacuum pre-loading, sehingga dapat meminimalisir kerusakan dengan melakukan analisis pada kedalaman PVD $5 \mathrm{~m}$ hingga $30 \mathrm{~m}$.

Dari penelitian tersebut diharapkan dapat mengetahui jarak pengaruh penurunan dan pergerakan lateral diluar daerah perbaikan dengan masing-masing kedalaman PVD.

\section{Berat jenis tanah $(\gamma)$ dan kadar air $(w)$}

Berat satuan dan kadar air dari tanah berkorelasi dengan derajat kepadatan, derajat saturasi, komposisi mineral dan kedalaman overburden. Secara teori, komposisi mineral dan derajat kepadatan di suatu perkotaan yang sama tidak jauh berbeda. Oleh karena itu, pada saat tanah di sekitar area perkotaan mendekati $100 \%$ jenuh, maka berat satuan jenuh dan kadar air akan memiliki kemiripan. Tetapi, semakin dalam suatu lapisan, maka semakin besar berat satuan, dan memiliki kadar air yang kecil. (Ou, 2006).

\section{Permeabilitas (k)}

Permeabilitas merupakan keadaan dimana air mampu untuk mengalir di tanah, dan merupakan salah satu sifat dasar tanah yang bisa dilihat pada Tabel 1 (Ou, 2006). Koefisien permeabilitas tergantung pada beberapa faktor, yaitu: kekentalan cairan, distribusi ukuran pori, distribusi ukuran butir, angka pori, kekasaran permukaan butiran tanah, dan derajat kejenuhan tanah. (Das, 1988).

Tabel 1. Koefisien permeabilitas (Sumber: Ou, 2006)

\begin{tabular}{ll}
\hline Soil Type & $\mathrm{k}(\mathrm{cm} / \mathrm{sec})$ \\
\hline Clean gravel & $>10^{-1}$ \\
Coarse to fine soil & $10^{-1}-10^{-3}$ \\
Fine sand, silty sand & $10^{-3}-10^{-5}$ \\
Silt, Silty clay & $10^{-4}-10^{-6}$ \\
Clay & $<10^{-7}$ \\
\hline
\end{tabular}

\section{Settlement}

Penambahan beban di atas suatu permukaan tanah dapat menyebabkan lapisan tanah di bawahnya mengalami pemampatan. Pemampatan tersebut disebabkan oleh adanya deformasi partikel tanah, relokasi partikel, keluarnya air atau udara dari dalam pori, dan sebab-sebab lain. Beberapa atau semua faktor tersebut mempunyai hubungan dengan keadaan tanah yang bersangkutan. Secara umum, penurunan (settlement) pada tanah yang disebabkan oleh pembebanan dapat dibagi dalam dua kelompok besar (Das, 1988), yaitu: penurunan konsolidasi dan penurunan segera.

\section{Penurunan konsolidasi}

Penurunan konsolidasi (consolidation settlement), yang merupakan hasil dari perubahan volume tanah jenuh air sebagai akibat dari keluarnya air yang menempati pori-pori tanah. Keluarnya air dari dalam pori selalu disertai dengan berkurangnya volume tanah, berkurangnya volume tanah tersebut dapat menyebabkan penurunan lapisan 
tanah itu. Karena air pori di dalam tanah berpasir dapat mengalir keluar dengan cepat, maka penurunan segera dan penurunan konsolidasi terjadi bersamaan. (Das, 1988).

Untuk lempung normally consolidated:

$$
S c=\frac{C c H}{1+e_{0}} \log \left(\frac{p_{o}+\Delta P}{p_{o}}\right)
$$

Untuk lempung over-consolidated:

(a) Bila $(\mathrm{Po}+\Delta \mathrm{p}) \leq \mathrm{Pc}$, maka

(b) Bila $(\mathrm{Po}+\Delta \mathrm{p}) \geq \mathrm{Pc}$, maka

$$
S c=\frac{C s H}{1+e_{0}} \log \left(\frac{p_{o}+\Delta P}{p_{o}}\right)
$$

$$
S c=\frac{C s H}{1+e_{0}} \log \frac{p_{o}}{p_{c}}+\frac{C s H}{1+e_{0}} \log \left(\frac{p_{o}+\Delta P}{p_{o}}\right)
$$

dengan $\mathrm{Cc}=$ indeks pemampatan, $\mathrm{Cs}=$ indeks pemuaian, $\mathrm{H}=$ tebal lapisan, $\mathrm{e}_{0}=$ angka pori awal pada saat volume tanah sama dengan $\mathrm{V}_{0}$, Po $=$ tekanan efektif, $\Delta \mathrm{p}=$ penambahan tekanan.

\section{Penurunan elastis}

Penurunan elastis merupakan akibat dari deformasi elastis tanah kering, basah, dan jenuh air tanpa adanya perubahan kadar air. Perhitungan penurunan segera umunya didasarkan pada penurunan yang diturunkan dari teori elastisitas. Besar penurunan elastis dapat dihitung dengan rumus sebagai berikut. (Gunawan, et. al., 2020)

$$
S i=\frac{\Delta \sigma}{M} H
$$

dengan $\Delta \sigma=$ tegangan total, $\mathrm{M}=$ constrained modulus

\section{Vacuum pre-loading}

Pada kondisi tertentu, pembebanan berupa timbunan diatas tanah lunak tidak dapat dilakukan, hal tersebut disebabkan oleh kondisi tanah dasar yang sangat lunak sehingga tidak memungkinkan untuk diberi beban timbunan walaupun dengan tinggi timbunan yang tidak seberapa tinggi. Untuk itu sistem pre-loading yang digunakan adalah bukan sistem convensional pre-loading, melainkan menggunakan metode vacuum pre-loading.

Prinsip penggunaan vacuum pre-loading pada tanah lempung lunak pertama kali diperkenalkan oleh W. Kjellman dari Swedish Geotechnical Institute pada tahun 1952. Pada metode ini, pembebanan menggunakan timbunan diganti dengan menggunakan tekanan atmosfir.

Peralatan ini terdiri dari sistem drainase vertikal dengan lapisan drainase diatasnya (lapisan pasir). Lapisan pasir tersebut ditutupi oleh lapisan yang kedap air. Drainase horizontal dipasang pada lapisan drainase dan berhubungan langsung dengan pompa vacuum. Untuk menjaga kelembapan udara, membrane kedap air itu ditempatkan pada dasar dari saluran yang diisi penuh dengan bentonite. Tegangan negatif akan terjadi pada lapisan drainase tersebut akibat proses pemompaan vacuum dapat dilihat pada gambar 1. Tegangan negatif tersebut akan menghasilkan negative pore water pressure, yang disebabkan oleh meningkatnya nilai tegangan efektif pada tanah sehingga dapat menyebabkan terjadinya konsolidasi pada tanah. (Indraratna, et.al., 2009)

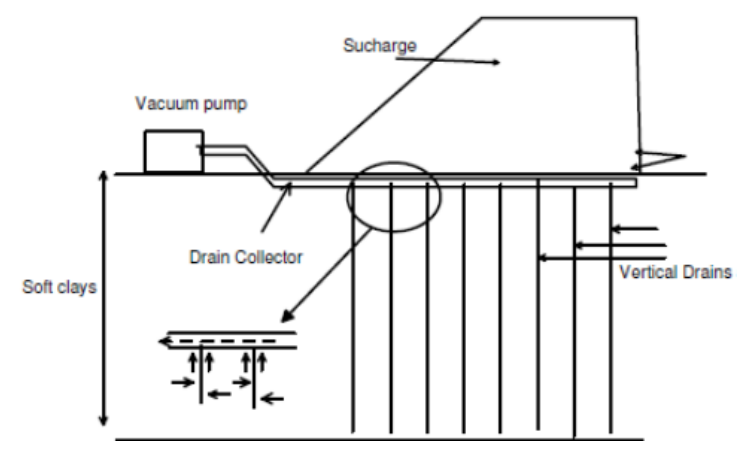

Gambar 1. Diagram metode vakum (Sumber: Indraratna, et.al., 2009)

Dalam analisis geoteknik, tekanan atmosfir sering diabaikan atau dianggap nol dalam hitungan tegangannya. Akan tetapi, dalam teori konsolidasi vakum, tekanan atmosfer perlu dipertimbangkan. Saat tekanan vakum diaplikasikan, tegangan vertikal tetap sama, akan tetapi tekanan pori berkurang. Besarnya kenaikan tegangan efektif sama dengan 
tekanan isapan dari pompa vakum dikalikan dengan nilai efisiensi. Umumnya, efisiensi pompa vakum berkisar antara 70 - 80\% dari tekanan atmosfer. (Chu \& Yan, 2005).

Keuntungan penggunakan sistem vacuum pre-loading ini adalah tidak diperlukannya material tambahan, waktu pelaksaan juga relatif lebih singkat selain itu peralatan yang digunakan bukan merupakan peralatan berat dan besar. Selain itu juga, tidak digunakan bahan kimia untuk stabilitas sehingga relative aman untuk lingkungan. (Chai, et. al., 2005).

Keuntungan lain dari penggunaan metode ini adalah konsolidasi secara isotropic dapat mengurangi resiko terjadinya keruntuhan akibat beban konstruksi diatasnya. Selain itu, resiko terjadinya keruntuhan pada talud juga bisa dihindari dengan melakukan kontrol terhadap pemampatan (Masse, et. al., 2001). Ada beberapa hal penting yang harus diperhatikan jika menggunakan metode ini (Masse, et. al., 2001) yaitu:

1. Untuk menjaga keefektifan pengaliran dibawah membrane, perlu dilakukan pengecekan dan pengaturan kadar air serta udara selama proses pemompaan.

2. Menjaga kondisi jenuh air pada tanah dibawah lapisan membrane.

3. Menjaga vacuum tetap pada level yang efektif.

4. Menjaga agar tidak terjadi kebocoran sama sekali peralatan vacuum maupun pada membrane pelapis.

5. Memperkuat dan melapisi sistem pada saluran disisi area yang akan di vacuum pre-loading.

\section{Vertical drain}

Karena memiliki permeabilitas yang rendah, tanah lempung akan mengalami konsolidasi dalam waktu yang lama. Untuk mempersingkat waktu konsolidasi, maka vertical drain dikombinasikan dengan pre-loading atau vacuum. Vertical drain adalah jalur drainase buatan yang dimasukan ke dalam lapisan tanah. Dengan demikian, pada saat konsolidasi air akan dikeluarkan dan mengalir melalui saluran vertikal, sehingga dapat mempercepat konsolidasi dan memperoleh peningkatan kekuatan. (Holtz, et.al., 1991).

\section{Prefabricated vertical drain (PVD)}

Prefabricated Vertical Drain dapat didefinisikan sebagai material atau produk sintetis yang terdiri dari lapisan filter (drain jacket) yang mengelilingi inti dengan karakteristik: a.) Kemampuan air tanah untuk meresap ke saluran pembuangan; b.) Sarana yang digunakan untuk mengalirkan air pori ke sepanjang saluran pembuangan. (Bergado, et.al., 1996).

Lapisan filter terdisi dari polyester yang berfungsi untuk memisahkan air dari tanah lunak disekitarnya dan filter berfungsi untuk membatasi perpindahan partikel halus ke dalam untuk mencegah penyumbatan.

PVD dapat digunakan pada pembangunan/pekerjaan di darat dan/atau di laut untuk tujuan sebagai berikut: (Badan Strandardisasi Nasional, 2017)

1. Mengurangi besaran penurunan setelah pembangunan.

2. Mempercepat proses konsolidasi dengan mengurangi panjang lintasan disipasi tegangan air pori berlebih.

3. Meningkatkan stabilitas (dengan menaikkan tegangan efektif dalam tanah).

4. Mengurangi/mitigasi efek likuifaksi.

PVD ini dapat dikombinasikan dengan metode perbaikan tanah lain, yaitu: elektro osmosis kolom pasir (compacted sand piles), kompaksi dinamik (dynamic compaction) dan deep mixing.

\section{METODE PENELITIAN}

\section{Pengolahan data}

Dari data tanah yang telah diperoleh, maka data tanah tersebut akan di korelasi untuk menentukan parameterparameter tanah, agar hasil dari pemodelan tersebut sesuai dengan yang didapatkan dari lapangan. Dari parameterparameter yang telah didapatkan, maka akan dilakukan beberapa pemodelan, model-model tersebut adalah:

1. Pemodelan aktual vacuum pre-loading dengan vertical drain.

2. Pemodelan modifikasi vacuum pre-loading dengan vertical drain, dengan kedalaman $5 \mathrm{~m}, 10 \mathrm{~m}, 15 \mathrm{~m}, 20$ $\mathrm{m}, 25 \mathrm{~m}$, dan $30 \mathrm{~m}$.

Langkah-langkah pengolahan data yang akan dilakukan adalah sebagai berikut:

1. Melakukan korelasi parameter dari data tanah yang diperoleh agar dapat melengkapi parameter-parameter.

2. Membentuk pemodelan vacuum pre-loading dengan PVD menggunakkan program elemen hingga 2D dengan parameter yang telah didapat agar sesuai dengan aktual, jika tidak sesuai maka dilakukan korelasi kembali. 
3. Membentuk pemodelan vacuum pre-loading dan PVD, dengan parameter-parameter yang telah sesuai dengan aktual.

4. Membentuk pemodelan vacuum pre-loading dan PVD, dengan kedalaman 5m, 10m, 15m, 20m, 25m, dan $30 \mathrm{~m}$.

5. Membandingkan hasil dari keluaran (output) jarak pengaruh dari program berdasarkan kedalaman masingmasing PVD.

\section{Diagram alir}

Langkah-langkah yang akan dilakukan pada penelitian digambarkan pada alir penelitian seperti pada Gambar 2.

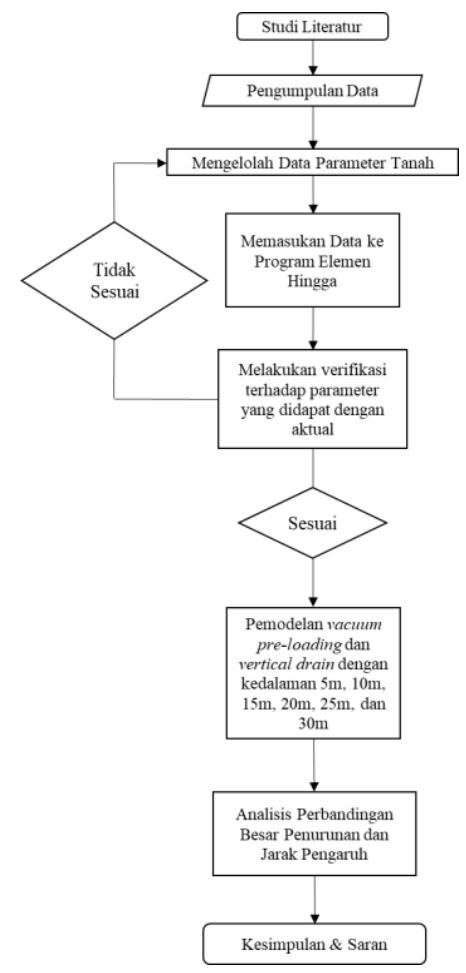

Gambar 2. Diagram alir penelitian

\section{HASIL DAN PEMBAHASAN}

\section{Parameter tanah}

Klasifikasi tanah yang ditentukan berdasarkan data investigasi tanah dengan jarak yang paling dekat ke lokasi tinjauan, diantaranya CPTe 3-4, CPTe 3-5, CPTu-03, BH-09 dan BH-10, dari data hasil investigasi tersebut di dapat jenis tanah dengan menggabungkan nilai besaran N-SPT dari masing-masing data tersebut dan selanjutnya diklasifikasikan. Berdasarkan hasil klasifikasi jenis-jenis tanah, maka dapat dipastikan jenis tanah tersebut dapat dilakukan perbaikan dengan metode vacuum pre-loading dan PVD berdasarkan Gambar 3. 


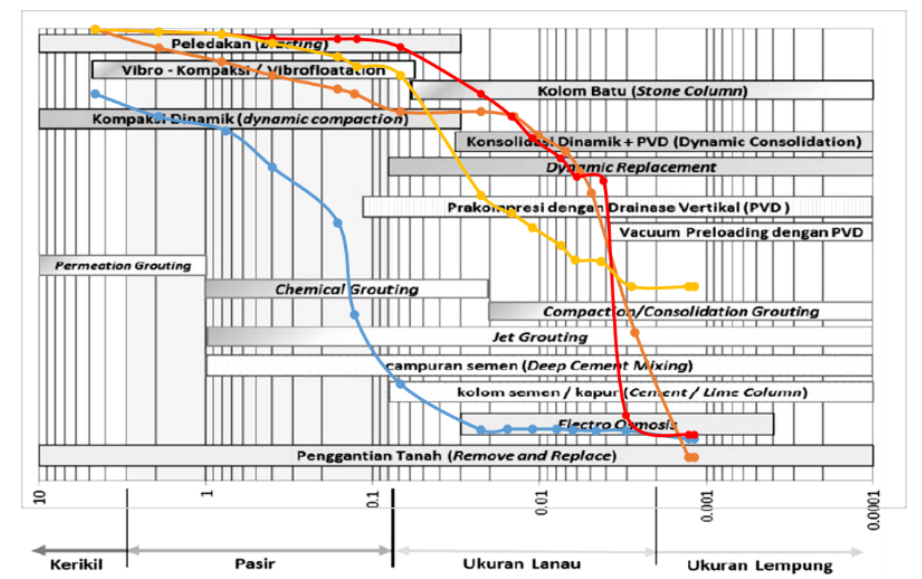

Gambar 3. Kriteria penetuan jenis perbaikan tanah dengan grain size (Sumber: SNI 8460:2017)

\section{Resume hasil analisis parameter tanah}

Berdasarkan data-data yang diperoleh dari hasil korelasi, dan analisis dari data hasil investigasi untuk menentukan parameter-parameter tanah yang akan digunakan pada program elemen hingga. Resume hasil analisis parameter tanah yang digunakan dapat dilihat pada Tabel 2. Namun, parameter yang digunakan untuk verifikasi hasil data lapangan pada analisis yaitu sampai kedalaman 29.3 meter.

Tabel 2. Resume hasil analisis parameter tanah

\begin{tabular}{|c|c|c|c|c|c|c|c|c|c|c|c|}
\hline $\begin{array}{c}\text { Lapisan } \\
\text { Tanah }\end{array}$ & \multicolumn{2}{|c|}{$\begin{array}{l}\text { Kedalaman } \\
\text { (m) }\end{array}$} & N-SPT & $\begin{array}{l}\text { Jenis } \\
\text { Tanah }\end{array}$ & \multicolumn{2}{|c|}{$\begin{array}{c}\text { Konsistensi } \\
\text { Tanah }\end{array}$} & \multicolumn{2}{|c|}{$\begin{array}{c}\gamma_{\text {sat }} \\
\left(\mathrm{kN} / \mathrm{m}^{2}\right)\end{array}$} & $\begin{array}{c}\gamma_{\text {unsat }} \\
\left(\mathrm{kNN} / \mathrm{m}^{2}\right)\end{array}$ & $\begin{array}{c}\mathrm{Kx}, \mathrm{Ky} \\
\text { (m/day) }\end{array}$ & Es $\left(\mathrm{kN} / \mathrm{m}^{2}\right)$ \\
\hline Lapisan 1 & \multicolumn{2}{|c|}{$0-4,8$} & 1 & Silty Clay & \multicolumn{2}{|c|}{ Very Soft } & \multicolumn{2}{|c|}{18} & 14 & $8,64 \times 10^{-5}$ & 2000 \\
\hline Lapisan 2 & \multicolumn{2}{|c|}{$4,8-15,9$} & 2 & Silty Clay & \multicolumn{2}{|c|}{ Soft } & \multicolumn{2}{|c|}{18} & 14 & $8,64 \times 10^{-5}$ & 2000 \\
\hline Lapisan 3 & \multicolumn{2}{|c|}{$15,9-18$} & 10 & Silty Clay & \multicolumn{2}{|c|}{ Stiff } & \multicolumn{2}{|c|}{18} & 14 & $8,64 \times 10^{-5}$ & 9300 \\
\hline Lapisan 4 & \multicolumn{2}{|c|}{$18-29,3$} & 12 & Silty Clay & \multicolumn{2}{|c|}{ Stiff } & \multicolumn{2}{|c|}{18} & 14 & $8,64 \times 10^{-3}$ & 54000 \\
\hline Lapisan 5 & \multicolumn{2}{|c|}{$29,3-37$} & 31 & Sand & \multicolumn{2}{|c|}{ Dense } & \multicolumn{2}{|c|}{18} & 14 & $8,64 \times 10^{-3}$ & 32500 \\
\hline Lapisan 6 & \multicolumn{2}{|c|}{$37-62$} & 25 & Silty Clay & \multicolumn{2}{|c|}{ Very Stiff } & \multicolumn{2}{|c|}{18} & 14 & $8,64 \times 10^{-5}$ & 100000 \\
\hline Lapisan 7 & $62-$ & 74,9 & 23 & Silty Clay & Very & tiff & & & 14 & $8,64 \times 10^{-5}$ & 100000 \\
\hline Lapisan 8 & 74,9 & 80,4 & 28 & Silty Clay & Very & itff & & & 15 & $8,64 \times 10^{-3}$ & 100000 \\
\hline $\begin{array}{c}\text { Lapisan } \\
\text { Tanah }\end{array}$ & $\mu$ & e & $\mathrm{Cc}$ & Cs & $\begin{array}{c}\mathrm{Su} \\
\left(\mathrm{kN} / \mathrm{m}^{2}\right)\end{array}$ & $(\mathrm{kN}$ & & $\phi($ & & OCR & $\mathrm{K}_{0}$ \\
\hline Lapisan 1 & 0,3 & 2,5 & 0,9 & 0,18 & 5 & se & & 30 & & 1 & 0,5 \\
\hline Lapisan 2 & 0,35 & 2,17 & 0,77 & 0,15 & 10 & the & & 25 & & 1,2 & 0,563 \\
\hline Lapisan 3 & 0,35 & 2,17 & 0,77 & 0,15 & 35 & , & & 30 & & 2 & 0,707 \\
\hline Lapisan 4 & 0,35 & 1,7 & 0,58 & 0,12 & 50 & 1 & & 30 & & 2,6 & 0,806 \\
\hline Lapisan 5 & 0,35 & 1,7 & 0,58 & 0,12 & 85 & & & 36 & & 3 & 0,866 \\
\hline Lapisan 6 & 0,35 & 1 & 0,3 & 0,06 & 110 & 2 & & 30 & & 3 & 0,866 \\
\hline Lapisan 7 & 0,5 & 1 & 0,3 & 0,06 & 105 & & & 30 & & 3 & 0,866 \\
\hline Lapisan 8 & 0,4 & 1 & 0,3 & 0,06 & 115 & 2 & & 30 & & 3 & 0,866 \\
\hline
\end{tabular}

\section{Hasil analisis program elemen hingga 2D}

Setelah semua tahapan pemodelan selesai di analsis, maka hasil penurunan dan pergerakan lateral dapat dilakukan verifikasi hasil terhadap parameter yang digunakan. Setelah hasil penurunan sesuai dengan data lapangan, maka parameter tersebut akan digunakan untuk analisis PVD dengan kedalaman 5 m, 10 m, 15m, 20 m, $25 \mathrm{~m}$, dan $30 \mathrm{~m}$ untuk menentukan jarak pengaruh lateral.

- Hasil Penurunan dan Pergerakan Lateral Pada Kedalaman 14,5 meter (Sesuai Data Lapangan) 
Data hasil analisis PVD dengan kedalaman 14,5 meter sesuai dengan data lapangan digunakan untuk melakukan verifikasi terhadap parameter yang digunakan. Berdasarkan analisis yang dilakukan dengan program elemen hingga terdapat 2 hasil analisis yaitu dengan model material Mohr-coulomb dan Soft soil model.

\section{- Mohr-Coulomb}

Berdasarkan analisis dengan model material Mohr-Coloumb, nilai penurunan telah menunjukan hasil yang sesuai dengan hasil monitoring, tetapi nilai pergerakan lateral yang dihasilkan dengan model material ini tidak sesuai dengan data monitoring. Hasil analisis dapat di lihat pada Gambar 4 dan 5.

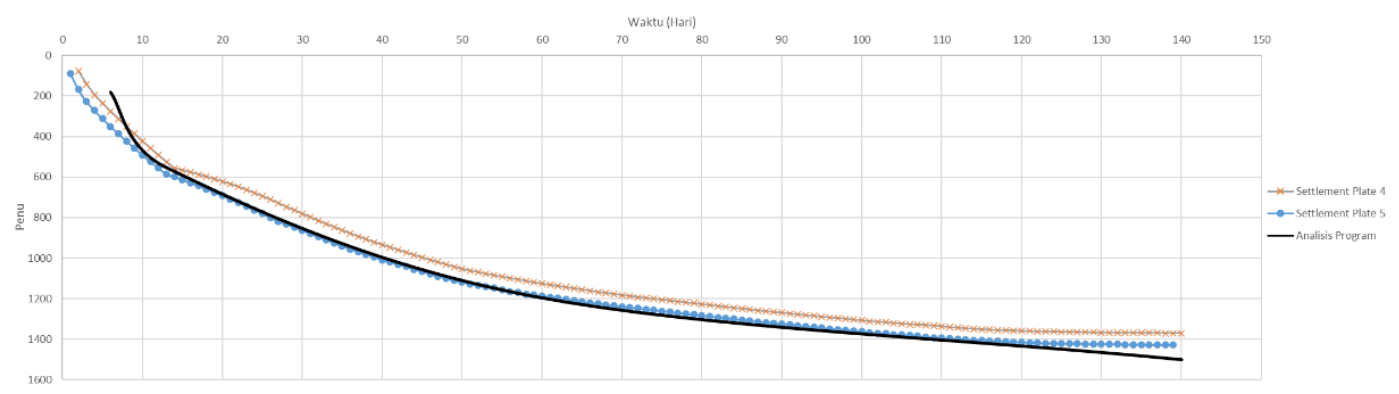

Gambar 4. Kurva perbandingan settlement terhadap waktu dengan mohr-coulomb

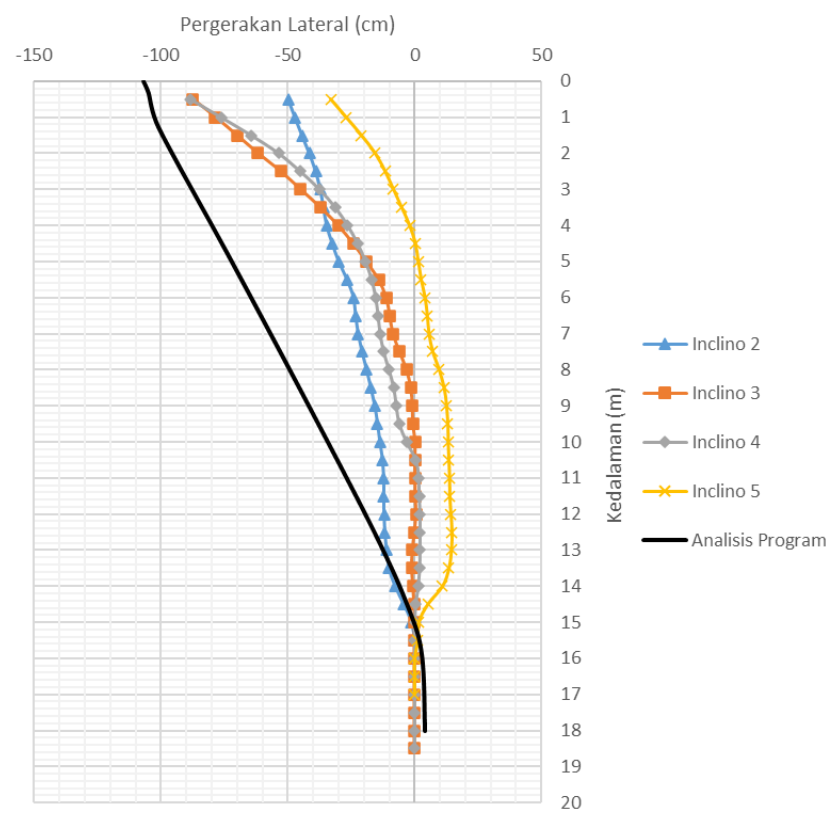

Gambar 5. Grafik perbandingan pergerakan lateral inklinometer dan hasil analisis dengan mohr-coulomb

\section{- Soft Soil Model}

Berdasarkan hasil analisis dengan model material Soft soil model, nilai penurunan dan pergerakan lateral telah menunjukan nilai yang sesuai dengan hasil monitoring. Pada hasil analisis dan hasil monitoring penurunan dapat dilihat pada Gambar 6 dan hasil pergerakan lateral yang dibandingkan dengan empat buah inklinometer yang dipasang disekitar daerah perbaikan dapat di lihat pada Gambar 7. 


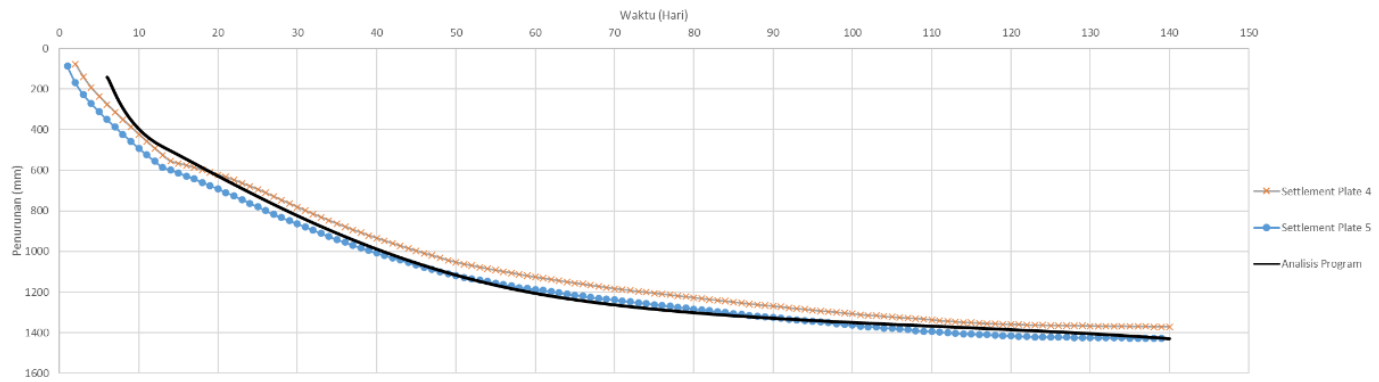

Gambar 6. Kurva perbandingan settlement terhadap waktu dengan soft soil model

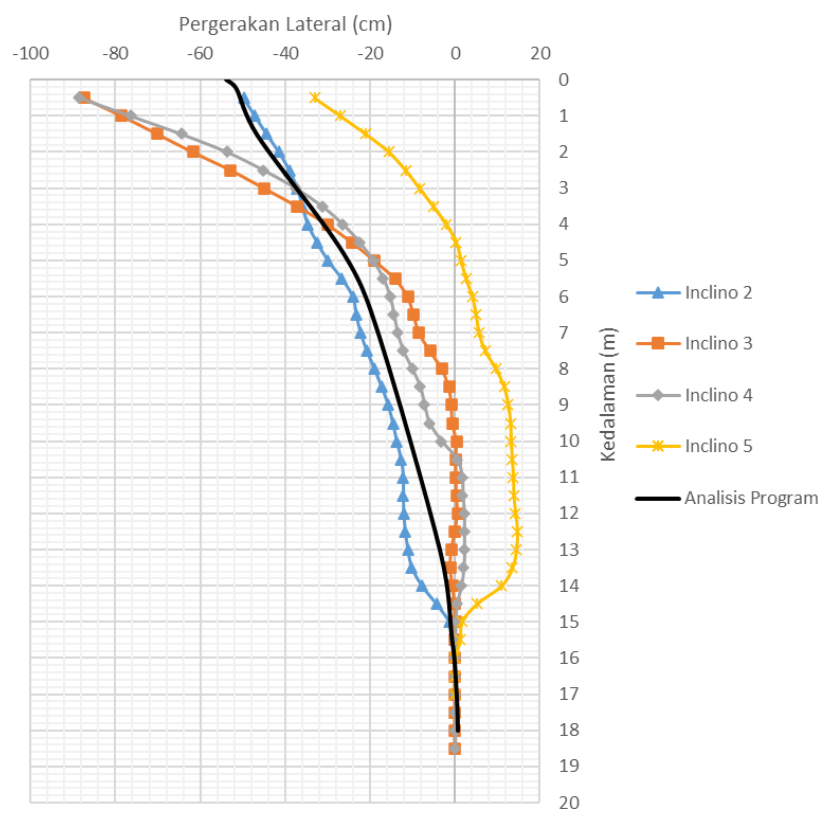

Gambar 7. Grafik perbandingan pergerakan lateral inklinometer dan hasil analisis dengan soft soil model

Namun, berdasarkan hasil penurunan dan pergerakan lateral, model material mohr-coulomb tidak sesuai dengan data monitoring, nilai penurunan yang didapat pada 140 hari perbaikan adalah 1,5 meter, sedangkan pada model material soft soil didapat nilai penurunan 1,43 meter. Maka, model yang akan digunakan pada analisis PVD dengan kedalaman 5 m, 10 m, 15 m, 20 m, 25 m, dan 30 m adalah Soft Soil Model, karena hasil analisis penurunan dan pergerakan lateral cukup sesuai dengan data monitoring. Nilai penurunan tiap fase pada masing-masing model material seperti pada Tabel 3.

Tabel 3. Hasil penurunan dan pergerakan lateral tiap fase

\begin{tabular}{cccc}
\hline Fase & Data Lapangan $(\mathrm{mm})$ & Soft Soil Model $(\mathrm{mm})$ & Mohr-Coulomb $(\mathrm{mm})$ \\
\hline 1 & 312 & 142,5 & 182,66 \\
2 & 555 & 483,9 & 551,74 \\
3 & 1134 & 1200 & 1190 \\
4 & 1428 & 1430 & 1500 \\
\hline
\end{tabular}

Dan setelah melakukan uji parameter agar mendapatkan nilai penurunan dan pergerakan lateral yang sesuai dengan data hasil monitoring, terdapat beberapa parameter yang di ubah untuk mencapai nilai penurunan yang sesuai seperti pada Tabel 4. 
Tabel 4. Parameter hasil verifikasi dengan data lapangan yang digunakan pada pemodelan

\begin{tabular}{ccccccccccc}
\hline \multirow{2}{*}{$\begin{array}{c}\text { Lapisan } \\
\text { Tanah }\end{array}$} & \multicolumn{2}{c}{$\gamma_{\text {sat }}\left(\mathrm{kN} / \mathrm{m}^{2}\right)$} & \multicolumn{2}{c}{$\mathrm{Kx}, \mathrm{Ky}(\mathrm{m} / \mathrm{day})$} & \multicolumn{2}{c}{$\mathrm{Es}\left(\mathrm{kN} / \mathrm{m}^{2}\right)$} & \multicolumn{2}{c}{$\mathrm{e}$} & \multicolumn{2}{c}{$\mathrm{Cc}$} \\
\cline { 2 - 11 } & Awal & Akhir & Awal & Akhir & Awal & Akhir & Awal & Akhir & Awal & Akhir \\
\hline Lapisan 1 & 18 & 14 & $8,64 \times 10^{-5}$ & $5,76 \times 10^{-5}$ & 2000 & 500 & 2,5 & 1,8 & 0,9 & 0,1 \\
Lapisan 2 & 18 & 16 & $8,64 \times 10^{-5}$ & $8,64 \times 10^{-5}$ & 2000 & 700 & 2,17 & 1,6 & 0,77 & 0,09 \\
Lapisan 3 & 18 & 16 & $1,25 \times 10^{-5}$ & $1,25 \times 10^{-5}$ & 9300 & 3720 & 2,17 & 1,5 & 0,77 & 0,06 \\
Lapisan 4 & 18 & 16 & $8,64 \times 10^{-3}$ & $8,64 \times 10^{-3}$ & 54000 & 13500 & 1,7 & 1,1 & 0,58 & 0,04 \\
\hline
\end{tabular}

\begin{tabular}{ccccccc}
\hline \multirow{2}{*}{$\begin{array}{c}\text { Lapisan } \\
\text { Tanah }\end{array}$} & \multicolumn{2}{c}{ Cs } & \multicolumn{2}{c}{ OCR } & \multicolumn{2}{c}{$\mathrm{K}_{0}$} \\
\cline { 2 - 7 } & Awal & Akhir & Awal & Akhir & Awal & Akhir \\
\hline Lapisan 1 & 0,18 & 14 & $8,64 \times 10^{-5}$ & $5,76 \times 10^{-5}$ & 2000 & 500 \\
Lapisan 2 & 0,15 & 16 & $8,64 \times 10^{-5}$ & $8,64 \times 10^{-5}$ & 2000 & 700 \\
Lapisan 3 & 0,15 & 16 & $1,25 \times 10^{-5}$ & $1,25 \times 10^{-5}$ & 9300 & 3720 \\
Lapisan 4 & 18 & 16 & $8,64 \times 10^{-3}$ & $8,64 \times 10^{-3}$ & 54000 & 13500 \\
\hline
\end{tabular}

Setelah mendapatkan hasil penurunan yang sesuai dengan data monitoring, di dapat resume parameter yang digunakan pada analisis lanjutan dengan kedalaman PVD 5 m, 10 m, 15 m, 20 m, 25 m, dan 30 m seperti pada Tabel 5 .

Tabel 5. Resume parameter hasil verifikasi dengan data lapangan yang digunakan pada analisis lanjutan

\begin{tabular}{ccccccccc}
\hline $\begin{array}{c}\text { Lapisan } \\
\text { Tanah }\end{array}$ & $\begin{array}{c}\text { Kedalaman } \\
(\mathrm{m})\end{array}$ & N-SPT & $\begin{array}{c}\text { Jenis } \\
\text { Tanah }\end{array}$ & $\begin{array}{c}\text { Konsistensi } \\
\text { Tanah }\end{array}$ & $\begin{array}{c}\left.\gamma_{\text {sat }}-\mathrm{k}^{2}\right) \\
\left(\mathrm{kN} / \mathrm{m}^{2}\right)\end{array}$ & $\begin{array}{c}\gamma_{\text {unsat }} \\
\left(\mathrm{kN} / \mathrm{m}^{2}\right)\end{array}$ & $\begin{array}{c}\text { Kx,Ky } \\
(\mathrm{m} / \mathrm{Kay})\end{array}$ & Es $\left(\mathrm{kN} / \mathrm{m}^{2}\right)$ \\
\hline Lapisan 1 & $0-4,8$ & 1 & Silty Clay & Very Soft & 14 & 14 & $5,76 \times 10^{-5}$ & 500 \\
Lapisan 2 & $4,8-15,9$ & 2 & Silty Clay & Soft & 16 & 14 & $8,64 \times 10^{-5}$ & 700 \\
Lapisan 3 & $15,9-18$ & 10 & Silty Clay & Stiff & 16 & 14 & $1,25 \times 10^{-5}$ & 3720 \\
Lapisan 4 & $18-29,3$ & 12 & Silty Clay & Stiff & 16 & 14 & $8,64 \times 10^{-3}$ & 13500 \\
\hline
\end{tabular}

\begin{tabular}{ccccccccccc}
\hline $\begin{array}{c}\text { Lapisan } \\
\text { Tanah }\end{array}$ & $\mu$ & $\mathrm{e}$ & $\mathrm{Cc}$ & $\mathrm{Cs}$ & $\begin{array}{c}\mathrm{Su} \\
\left(\mathrm{kN} / \mathrm{m}^{2}\right)\end{array}$ & $\begin{array}{c}\mathrm{c} ' \\
\left(\mathrm{kN} / \mathrm{m}^{2}\right)\end{array}$ & $\phi\left(^{\circ}\right)$ & $\psi\left({ }^{\circ}\right)$ & OCR & $\mathrm{K}_{0}$ \\
\hline Lapisan 1 & 0,3 & 1,8 & 0,52 & 0,1 & 5 & 1 & 30 & 0 & 1,38 & 0,587 \\
Lapisan 2 & 0,35 & 1,6 & 0,42 & 0,09 & 10 & 2 & 29 & 0 & 1,6 & 0,647 \\
Lapisan 3 & 0,35 & 1,5 & 0,3 & 0,06 & 35 & 7 & 30 & 0 & 2 & 0,707 \\
Lapisan 4 & 0,35 & 1,1 & 0,2 & 0,04 & 50 & 10 & 30 & 0 & 2,6 & 0,806 \\
\hline
\end{tabular}

- Hasil Penurunan dan Pergerakan Lateral Pada Kedalaman 5 m, 10 m, 15 m, 20 m, 25 m, dan 30 m

Pada hasil analisis PVD dengan kedalaman $5 \mathrm{~m}, 10 \mathrm{~m}, 15 \mathrm{~m}, 20 \mathrm{~m}, 25 \mathrm{~m}$, dan $30 \mathrm{~m}$ didapat hasil penurunan maksimum dan pergerakan lateral maksimum pada jarak 2,5 meter dari batas perbaikan seperti pada Tabel 6 .

Tabel 6. Hasil penurunan dan pergerakan lateral maksimum

\begin{tabular}{ccc}
\hline $\begin{array}{c}\text { Kedalaman } \\
(\mathrm{m})\end{array}$ & $\begin{array}{c}\text { Hasil Penurunan* } \\
(\mathrm{cm})\end{array}$ & $\begin{array}{c}\text { Hasil Pergerakan Lateral } \\
(\mathrm{cm})\end{array}$ \\
\hline 5 & 102 & 27,07 \\
10 & 140 & 62,05 \\
15 & 164 & 88,01 \\
20 & 187 & 89,7 \\
25 & 190 & 117,51 \\
30 & 204 & 122,37 \\
\hline
\end{tabular}

catatan: *nilai penurunan maksimum pada daerah tengah area perbaikan;

**nilai pergerakan lateral maksimum pada jarak 2,5 meter dari batas perbaikan

Nilai penurunan maksimum terdapat pada gambar potongan horizontal dan potongan vertikal dengan nilai tiap kedalaman dapat dilihat pada Gambar 8 dan Gambar 9. 
Studi Parametrik Jarak Pengaruh Penurunan dan Pergerakan Mario Oktavianus Lay, et al. Lateral akibat Vacuum Pre-loading pada Damage Area Sekitar

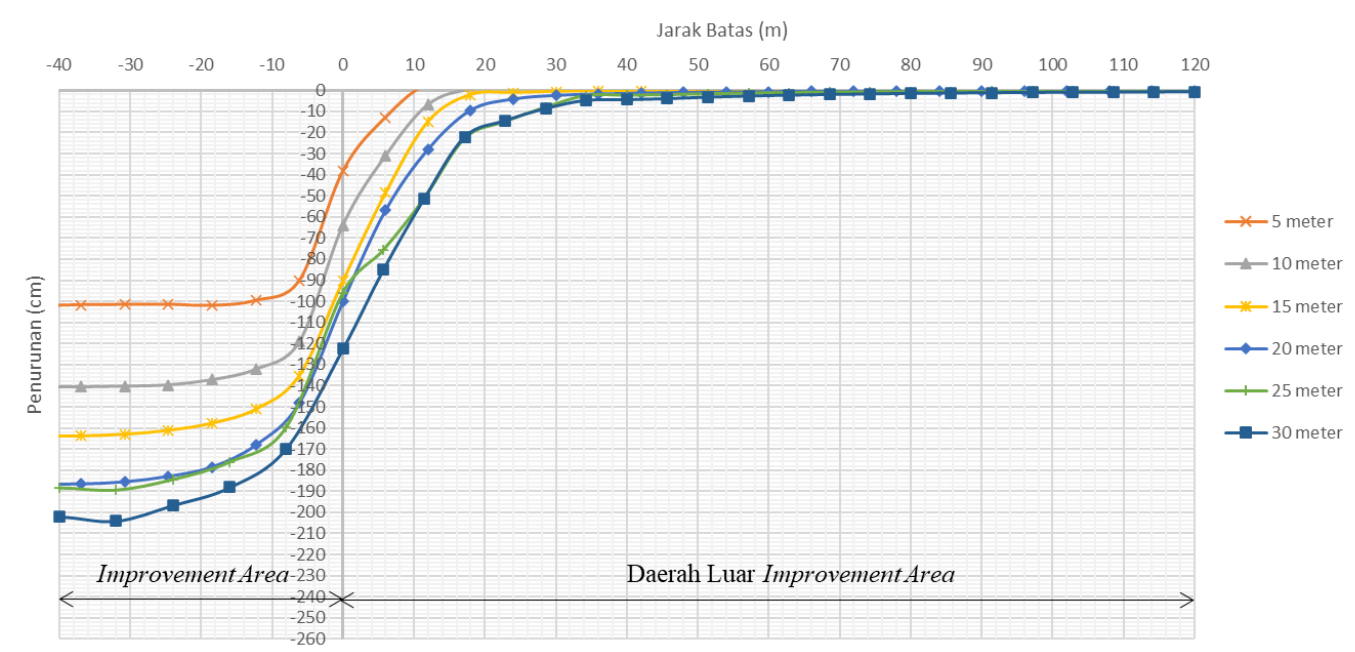

Gambar 8. Potongan horizontal settlement pada muka tanah setiap kedalaman PVD

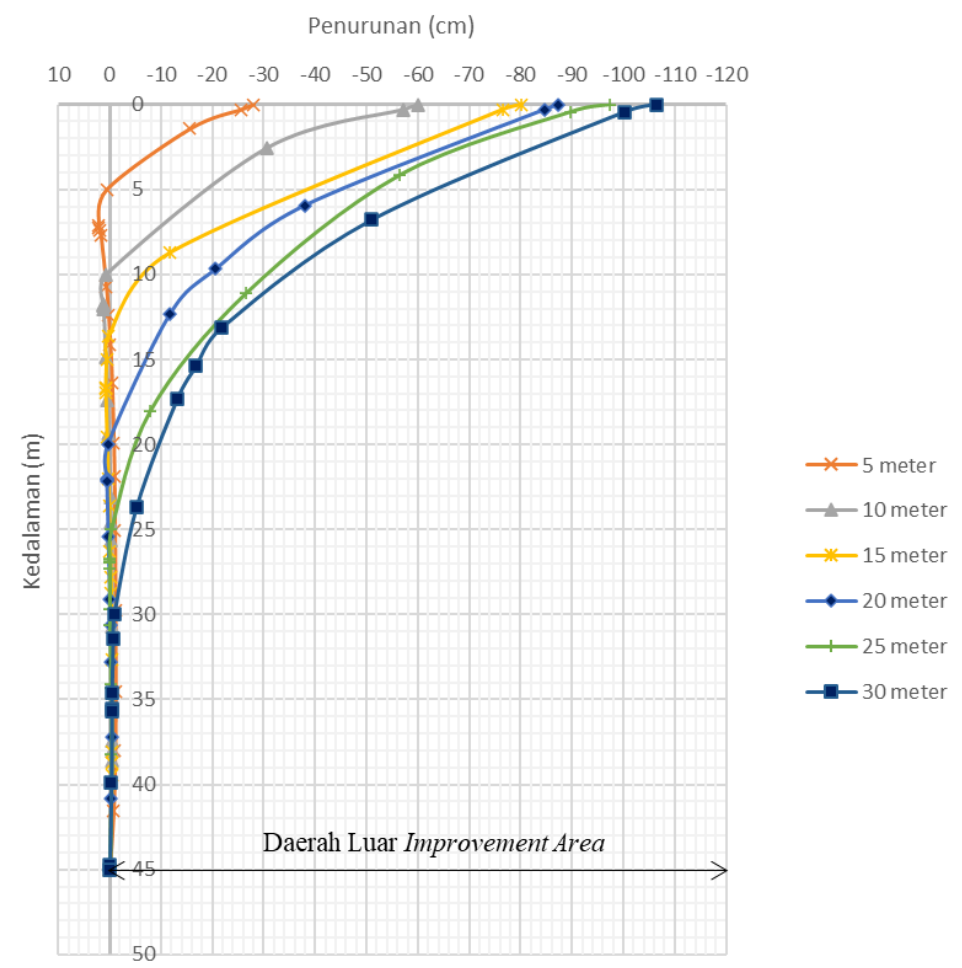

Gambar 9. Potongan vertikal settlement setiap kedalaman PVD

Hasil analisis pergeseran lateral terdapat 2 potongan, arah vertikal dan arah horizontal dapat dilihat pada Gambar 10 dan Gambar 11. 


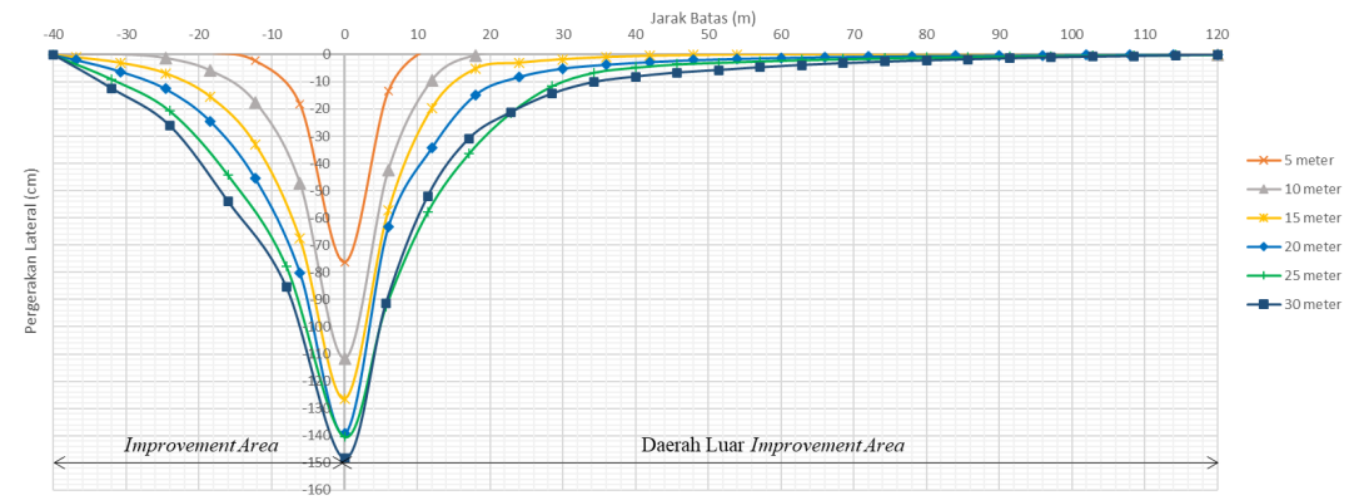

Gambar 10. Potongan horizontal pergerakan lateral tanah pada setiap kedalaman PVD

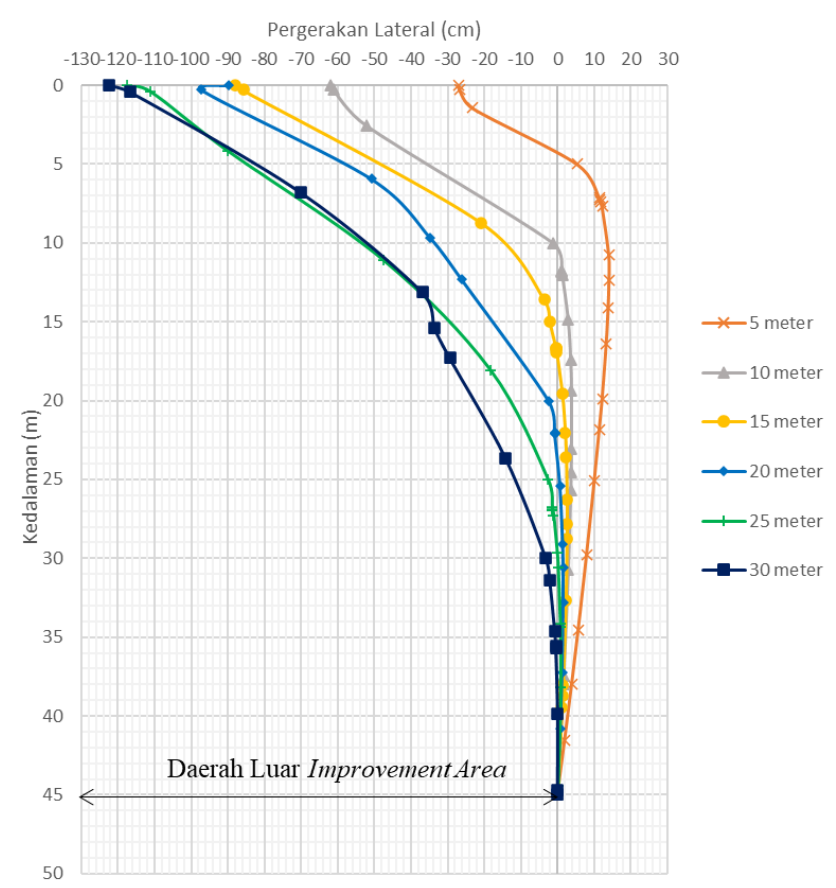

Gambar 11. Potongan vertikal pergerakan lateral tanah pada setiap kedalaman PVD

Berdasarkan hasil analisis pada PVD dengan kedalaman $5 \mathrm{~m}, 10 \mathrm{~m}, 15 \mathrm{~m}, 20 \mathrm{~m}, 25 \mathrm{~m}$, dan $30 \mathrm{~m}$, maka di dapat jarak pengaruh penurunan hingga kurang dari $2 \mathrm{~cm}$ dan pergerakan lateral hingga kurang dari $2 \mathrm{~cm}$ di luar batas lahan perbaikan dapat dilihat pada Gambar 12 dan Gambar 13, dan Hasil analisis dapat di lihat pada Tabel 7. 


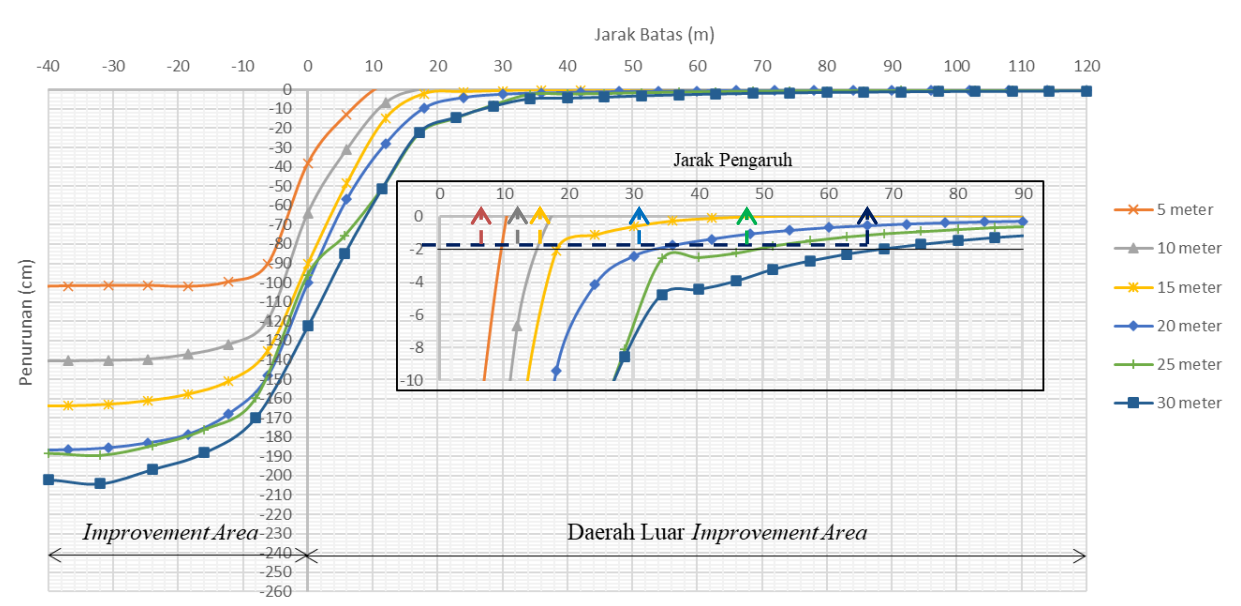

Gambar 12. Analisis jarak pengaruh akibat penurunan

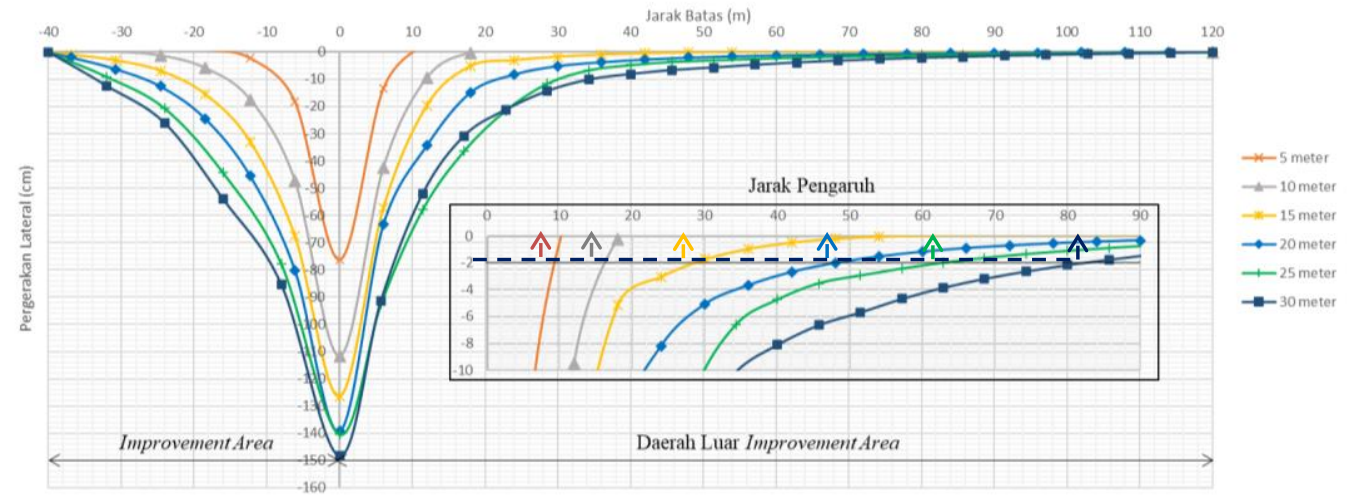

Gambar 13. Analisis jarak pengaruh akibat pergerakan lateral

Tabel 7. Hasil analisis jarak pengaruh penurunan dan pergerakan lateral di luar daerah perbaikan

\begin{tabular}{ccc}
\hline Kedalaman PVD & \multicolumn{2}{c}{ Jarak Pengaruh } \\
\cline { 2 - 3 }$(\mathrm{m})$ & Penurunan* & Pergerakan Lateral** \\
\hline 5 & $9,8 \mathrm{~m}$ & $9,5 \mathrm{~m}$ \\
10 & $15 \mathrm{~m}$ & $16 \mathrm{~m}$ \\
15 & $18 \mathrm{~m}$ & $28 \mathrm{~m}$ \\
20 & $33,5 \mathrm{~m}$ & $49,5 \mathrm{~m}$ \\
25 & $49 \mathrm{~m}$ & $63 \mathrm{~m}$ \\
30 & $69 \mathrm{~m}$ & $83 \mathrm{~m}$ \\
\hline
\end{tabular}

catatan: *jarak pengaruh dihitung dari batas perbaikan hingga penurunan $<2 \mathrm{~cm}$

**jarak pengaruh dihitung dari batas perbaikan hingga pergerakan lateral $<2 \mathrm{~cm}$

Berdasarkan hasil analisis tersebut, dapat dilihat sketsa tampak atas jarak pengaruh akibat penurunan dan pergerakan lateral seperti pada Gambar 14 dan 15. 
Jarak Pengaruh ( $\mathrm{m}$ )

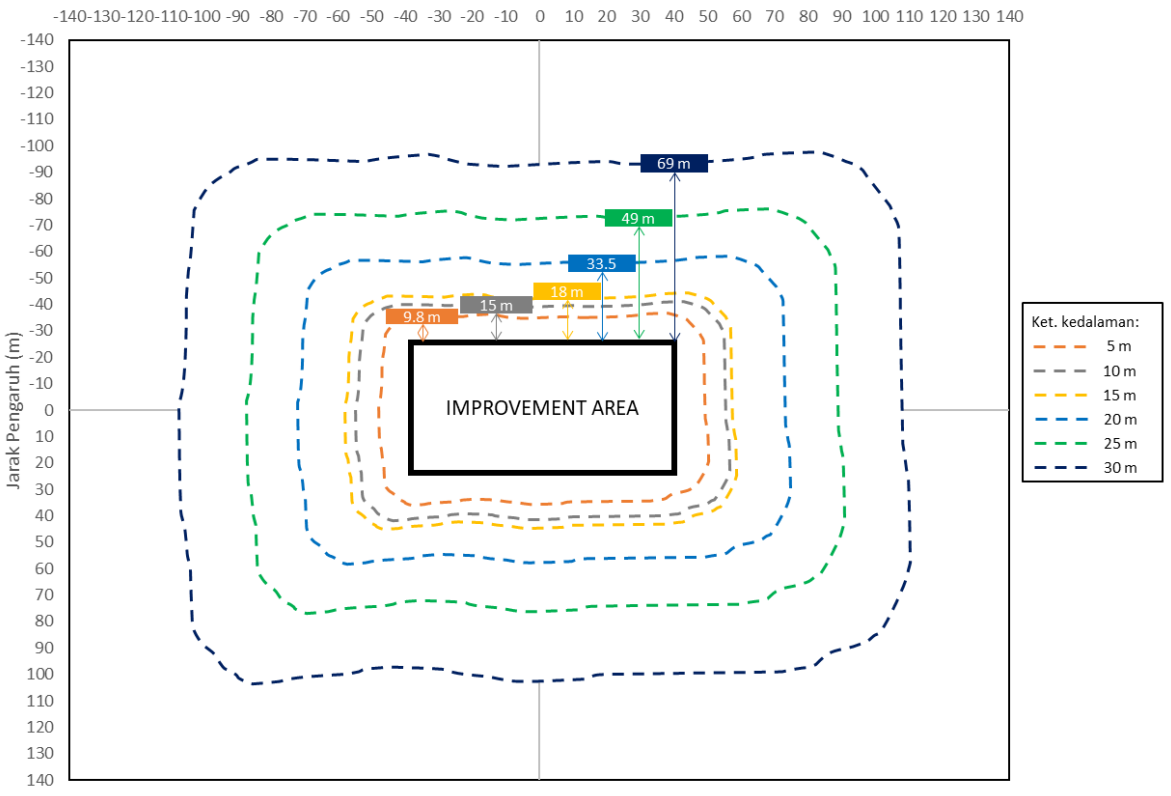

Gambar 14. Sketsa jarak pengaruh akibat penurunan

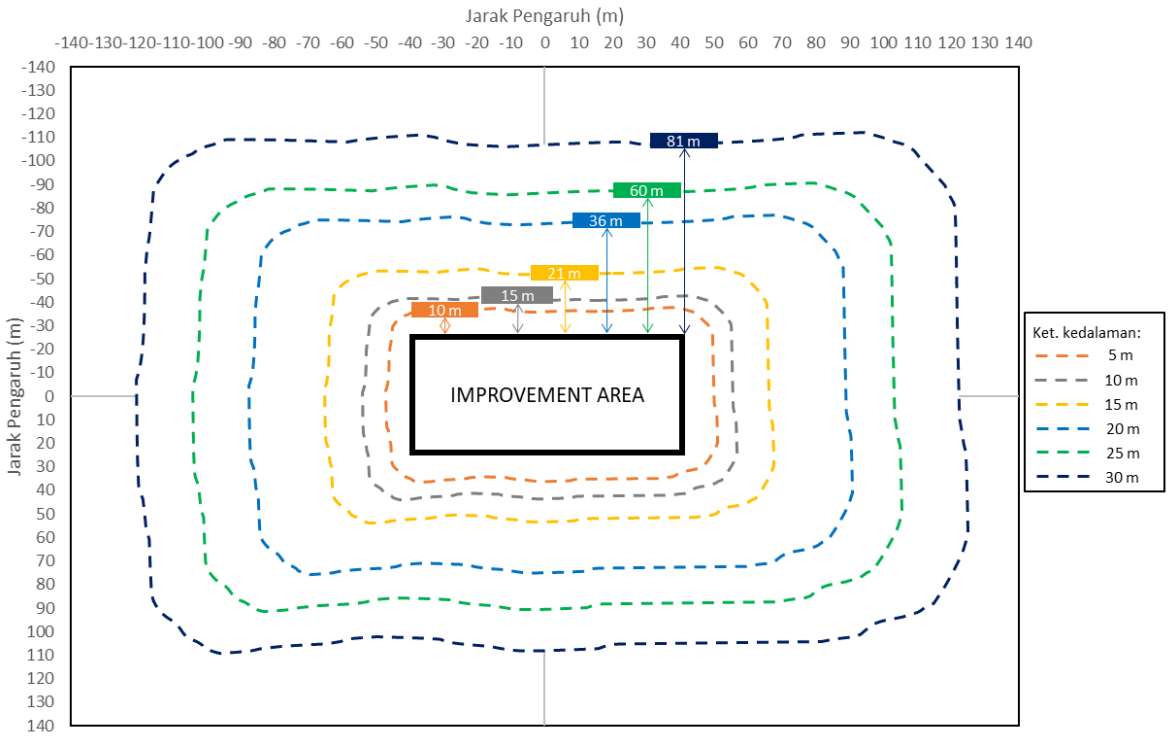

Gambar 15. Sketsa jarak pengaruh akibat pergerakan lateral

\section{KESIMPULAN DAN SARAN}

\section{Kesimpulan}

Berdasarkan hasil analisis dengan menggunakan program elemen hingga 2D, maka dapat di tarik kesimpulan yang bisa dilihat pada Tabel 7 di atas dan direkap di bawah yaitu:

1. Jarak pengaruh penurunan yang di ukur hingga penurunan yang terjadi kurang dari $2 \mathrm{~cm}$ akibat vacuum preloading terhadap area di luar batas lahan perbaikan dengan kedalaman PVD $5 \mathrm{~m}, 10 \mathrm{~m}, 15 \mathrm{~m}, 20 \mathrm{~m}, 25 \mathrm{~m}$, dan $30 \mathrm{~m}$ adalah: 
Studi Parametrik Jarak Pengaruh Penurunan dan Pergerakan

Mario Oktavianus Lay, et al.

Lateral akibat Vacuum Pre-loading pada Damage Area

Sekitar

\begin{tabular}{cc}
\hline $\begin{array}{c}\text { Kedalaman PVD } \\
(\mathrm{m})\end{array}$ & $\begin{array}{c}\text { Jarak Pengaruh akibat Penurunan } \\
(\mathrm{m})\end{array}$ \\
\hline 5 & $9,8 \mathrm{~m}$ \\
10 & $15 \mathrm{~m}$ \\
15 & $18 \mathrm{~m}$ \\
20 & $33,5 \mathrm{~m}$ \\
25 & $49 \mathrm{~m}$ \\
30 & $69 \mathrm{~m}$ \\
\hline
\end{tabular}

2. Jarak pengaruh pergerakan lateral yang di ukur hingga nilai pergerakan lateral yang terjadi kurang dari $2 \mathrm{~cm}$ akibat vacuum pre-loading terhadap area di luar batas lahan perbaikan dengan kedalaman PVD 5 m, 10 m, 15 $\mathrm{m}, 20 \mathrm{~m}, 25 \mathrm{~m}$, dan $30 \mathrm{~m}$ adalah:

\begin{tabular}{cc}
\hline $\begin{array}{c}\text { Kedalaman PVD } \\
(\mathrm{m})\end{array}$ & $\begin{array}{c}\text { Jarak Pengaruh akibat Pergerakan Lateral } \\
(\mathrm{m})\end{array}$ \\
\hline 5 & $9,5 \mathrm{~m}$ \\
10 & $16 \mathrm{~m}$ \\
15 & $28 \mathrm{~m}$ \\
20 & $49,5 \mathrm{~m}$ \\
25 & $63 \mathrm{~m}$ \\
30 & $83 \mathrm{~m}$ \\
\hline
\end{tabular}

\section{Saran}

Berdasarkan hasil analisis yang telah dilakukan, Adapun saran untuk melengkapi studi ini adalah:

1. Pada saat melakukan meshing dapat di buat dengan lebih detail lagi agar hasil yang didapatkan lebih akurat.

2. Studi lebih lanjut diperlukan untuk memodelkan proses unloading pada vacuum pre-loading, sehingga pemodelan dapat dilanjutkan untuk tahap konstruksi selanjutnya.

3. Studi dapat dikembangkan untuk memperoleh metode-metode penanganan agar pengaruh deformasi lateral akibat vacuum pre-loading dapat dikurangi atau dihilangkan.

\section{DAFTAR PUSTAKA}

Badan Strandardisasi Nasional. Persyaratan Perancangan Geoteknik. BSN, 2017.

Bergado, D.T., et al. Soft Ground Improvement in Lowland and Other Environment. 1996.

Chai, J.C., J.P. Carter dan S. Hayashi. "Ground Deformation induced by Vacuum Consolidation." Journal of geotechnical and geoenvironmental engineering (2005).

Chu, J. dan S. W. Yan. "Estimation of Degree of Consolidation for Vacuum Preloading Projects." International Journal of Geomechanics (2005).

Das, Braja M. Mekanika Tanah (Prinsip-prinsip Rekayasa Geoteknik). 1988.

Gunawan, Tomy, Alfred Jonathan S. dan Ali Iskandar. "Analisis Penurunan Pada Timbunan Dengan Prefabricated Vertical Darin (PVD) Menggunakan Data Hasil Uji CPTu." Jurnal Mitra Teknik Sipil (2020): 69-80.

Holtz, R.D. "Prefabricated Vertical Drains: Design and Performance." CTRIA ground engineering report: Ground improvement (1991).

Indraratna, Buddhima, Rujikiatkamjorn dan R. Kelly. "Modelling of Combined Vacuum and Surcharge Preloading with Vertical Drains." (2009).

Masse, F., et al. "Vacuum consolidation: A review of 12 years of successful development." ASCE (2001).

Ou, Chang-Yu. Deep Excavation Theory and Practice. London: Taylor \& Francis Group, 2006. 